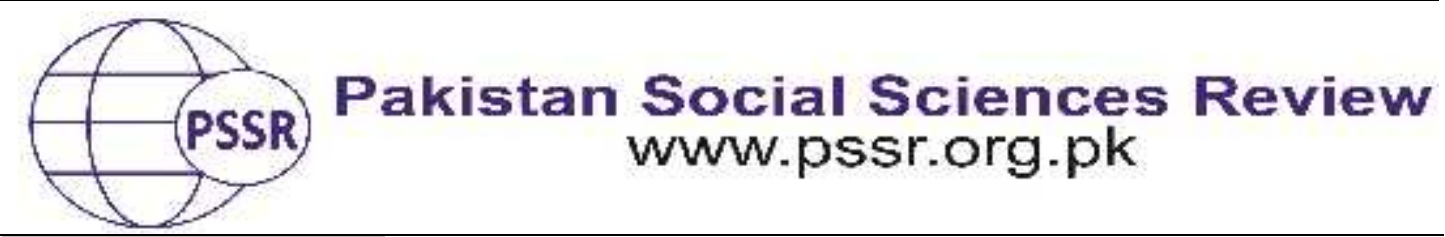

RESEARCH PAPER

\title{
Child Abuse in Schools of Pakistan: Exploring Reasons and Suggesting Measures
}

\author{
Nadia Rafique ${ }^{1}$ Dr. Muhammad Naeem Ashraf ${ }^{2}$ AnilaYasmin ${ }^{3}$
}

1. Headmistress, Government M.C Girls High School, Millat Colony Faisalabad, Punjab, Pakistan

2. Assistant Professor, Department of Education, Government Postgraduate College Samundri, Faisalabad, Punjab, Pakistan

3. Lecturer, Department of Education, Government College for Women Peermahal, TTS, Punjab, Pakistan

\begin{tabular}{|c|c|}
\hline PAPER INFO & ABSTRACT \\
\hline Received: & The Educational Managers, Teachers and Parents are worried \\
\hline May22, 2020 & to view a painful condition of child abuse in the schools of \\
\hline Accepted: & Pakistan. Protecting school going children from such \\
\hline $\begin{array}{l}\text { August 25, } 2020 \\
\text { Online: }\end{array}$ & maltreatment and evils are our basic and shared responsibility. \\
\hline $\begin{array}{l}\text { Unline: } \\
\text { September 15, } 2020\end{array}$ & Therefore the role of educators averting child abuse is more \\
\hline Keywords: & The present study explored four major \\
\hline Emotional Abuse & ouse in primary schools. The Participants \\
\hline Physical Abuse, & of students, whereas the sample \\
\hline $\begin{array}{l}\text { Psychological } \\
\text { Abuse, }\end{array}$ & was taken through convenience sampling method. The Focused \\
\hline Sexual Abuse & Group Discussion and Semi structured interview sheets were \\
\hline Corresponding & \\
\hline Author & $\begin{array}{l}\text { subjected to abuse on a regular basis in our schools. Findings } \\
\text { also revealed that the physical abuse happened moderately } \\
\text { while emotional abuse occurred more frequently. Moreover } \\
\text { physiological and sexual abuse was the part of our schools. }\end{array}$ \\
\hline
\end{tabular}

\section{Introduction}

Child abuse is such a global issue that it has affected children beyond any distinction of caste, colour and creed, ethnicity and every socio economic class (Collin-Vezina, Diagneault, Hebert, 2013). It appears in different forms such as physical and emotional, psychological and sexual abuse. It has most devastating impact upon health of children (Habetha et al., 2012).The senate of Pakistan passed the Criminal Law Amendment Bill 2015 which may be beneficial in putting much needed sanctions against child abuse in Pakistan. This bill has risen the age of criminal blame from seven to ten year of age, which has also suggested significant changes in Pakistan Penal Code. This bill has declared sexual assault upon minors 
punishable by seven years' incarceration whereas only rape was criminalized earlier on. Child pornography is also punishable for seven year imprisonment with a fine of Rs. 700,000. Child trafficking within the country is also recognized as criminal act. Earlier on only removing from country was held as a crime. Pakistan has 40 percent of its population under the age of 18, so such a law was already needed. Pakistan has been a signatory country to the International Convention on Child Abuse since 1990, but laws were not sufficiently enough to protect small children from sexual assault of the adults or older children in society.

This study was designed to focus how to deal with the consequences of child abuse and enables the targeted child to come out of this trauma. The incidents of child abuse are now widely spreading in our society. Every day newspapers are full of such incidents and TV channels also report such incidents on daily basis. Children have been physically, emotionally and sexually abused by adults. Children have become the victim of physical abuse at their home by parents or elders and in educational institutes by teachers. Mostly children bear this abuse silently. Some children also run away from their homes and schools as well to get rid of this pain. Child has also an ego and self-respect. By emotional abuse adult hurt the feelings of child which results in the lack of confidence in children.

This study is significant on the ground that it assists the teachers to assess the present child protection strategies, policies, practices and procedures to formulate a comprehensive child protection plan with effective measures for their schools. This study focuses on development of training module to teachers to minimize or control the child abuse, because in institutions no attention is paid to this problem. Teachers are not properly trained and they are unable to know about child abuse cannot help the child to come out of this trauma. Teachers' training is important because teachers have direct contact with students than any other person. Children also spend more time in schools with teachers more than their family members. So their opportunity to help, protect the health and safety of their students through intervention is great. Teachers have more opportunity to identify abuse. But due to lack of training there are many hurdles that prevent the teachers to report the child abuse. Children cannot perform their role effectively. One of the main reasons is the lack of proper knowledge and experience regarding the recognition of signs and symptoms of abuse. Teachers training are the fundamental element for implementing effective child protection program, so this study aims to groom teachers' professional knowledge and skills regarding child abuse for protecting students from unsafe and abusive situation in and outside of the school. It helps the teachers how to respond positively and supportively to students who may be experiencing abuse or who disclose maltreatment.

\section{Literature Review}

Abuse is also taken as an injury which results from punching or striking, may be beating and kicking or harming child in whichever way. The physical punishment has also direct link with physical abuse. This may also be due to the fact that the caregiver is doing so with the intention of giving discipline. The 
punishment can be unfortunate and inappropriate with child's age or condition. The risk factors between physical abuse and punishments are almost similar. They are detrimental for physical and mental health of a child (Durrant \& Ensom, 2012). The parents who inflict physical punishment upon their children, they themselves were liable to do so in their times. Over past many decades there is increased awareness among people about adverse effect of physical abuse upon health of children. It destroys child's psychological and physiological health. Teachers in beating action had found many times which seems to be the culture of classroom and school. Concept of corporal punishment did not diminished completely. Even it's being exercised in schools and homes for discipline and obedience as well (Bosede, 2010).

Physical abuse is prevalent almost everywhere. The students of selected Primary Schools at Switzerland revealed some hidden facts in a study that 40 percent of this population has undergone from some forms of child abuse during their life time. Some quotes of the society also exposed that child abuse still prevailing in obscure manner (Dlamini et. al., 2007). In the U.S.A child abuse considerably observed in school children by principals, teachers, coaches, bus drivers, caregivers (Grant et al., 2017).

If we try to find relation between physical punishment of mental health problems child and we should also enhance this issue relating to adult mental health issues. It may also have their roots in the same punishment of childhood. In adulthood such symptom may also appear in the form of depression, alcoholism, suicidal trend and low self-esteem. The students of selected Primary Schools at Switzerland revealed some hidden facts in a study that 40 percent of this population has undergone from some forms of child abuse during their life time. Some quotes of the society also exposed that child abuse still prevailing in obscure manner (Sooryanarayana et. al., 2017). Abused children have to face psychological problems like posttraumatic stress disorders, depression, anxiety and regressive behaviour (Cheah \&Choo, 2016).

Emotional abuse is most likely for children between the age of 16-17, or living in joint family or may have divorced parents (Ba-Saddik \& Hattab, 2012). A recent study in India exposed that ratio of $47.9 \%$ boys and $52.1 \%$ girls were likely to be emotionally and psychologically abused in schools. Although emotional abuse remain secreted but appear in the form of child's insight of relationship, selfawareness, flexibility, growth and mental strength, depression, parental abuse of drugs (Rees, 2010). Affection is the main point of emotional abuse. Parental behavior if it is inappropriate may have damaging effects upon the personality of child which may lead to severe complexities. Parental positive interaction is necessary for good upbringing of the child (Meintjes et. al., 2010).

In schools the child has to face troubles due to readymade views of the parents about superiority of the boys and restrictions of the girls and in the same way the disturbance a child may have in school may be due to extra confidence 
given by parents at home or threatening he is receiving at home. Previous researchers found that abused students have poorer performance in academic achievements when they are forcefully compared to their other fellows (Tanaka, Georgiades, Boyle, \& MacMillan, 2015).

Psychological abuse is a stifle which may stop the process of the growth of the individual. If conducive atmosphere is not available, strain, stress from society and family can lead to development of rigid and distorted perspective of self. If a student is rejected, ignored and spanned, such treatment will demolish the characteristics of good behavior specified by Rogers. It will hamper process of development and productivity. For this we shall have to concentrate upon positive class room activity for sound teacher - student interaction. Self-concept and selfconfidence is very important but psychological abuse may disturb and top such acquisition. It may impart long lasting impression upon the student in the process of personality building which is no doubt adverse (Pur, Liman\& Ali, 2016).

\section{Material and Methods}

\section{Research Design}

The following research was carried out with the help of data collection by using qualitative instruments like a focused group discussion sheet, an interview protocol. The main purpose for adopting qualitative approach was to know in depth perception, consistence and authentication of reliable results of the study.

\section{The Participants in Context}

The Participants of the study were consisted of Teachers, Educational Mangers and Parents of students in Faisalabad district. The sample of focused group discussions and interviews was taken by using convenience sampling technique. Two sessions having 27 participants were arranged for focused group discussion. All the educational managers of two Tehsils (City \&Sadar) of district Faisalabad were invited to participate in Focused Group Discussion (FGD) through invitation letter. A session of FGD was arranged in rural area and another session was arranged in urban area. The interview protocol was conducted with 23 parents of students who were taken to know their opinion regarding child abuse by applying convenience sampling technique both from rural and urban areas of the study. The objectives enclosed in the study were as following;

1. Recording the perception of Educational managers and Parents regarding child abuse

2. Recognizing various factors which contribute to child abuse

3. Assessing the need of training program to reduce child abuse 


\section{Instrumentation}

In the presence of existing literature a sheet of focused grouped discussion was developed which brought into light the various dimensions of child abuse. Focused group discussion which helped and investigated various factors involved in child abuse. Focused group discussion with educational managers also helped the researchers to identify the need of the study and factors contributing child abuse in cultural context of Pakistan. The researchers developed a series of questions regarding various dimensions of child abuse.

In order to get more clear and bright picture of child abuse in public schools a semi structured interview protocol was also developed to record the perception of parents regarding their awareness about child abuse. The semi structured interview revealed several causes, factors and symptoms of child abuse at early schooling of children. A series of questions were formed to explore observation of parents regarding child abuse.

\section{Results and Discussion}

\section{Summary of Focused Group Discussion}

The Participants revealed deep concerns about the existing condition of child abuse and child maltreatment among primary students, they shared several experiences which showed many non-accidental behaviors by parents / care givers, other adults or older adolescents that were outside the norms of conduct and entails a substantial risk of causing physical or emotional harm to a child. Child abuse remains prevalent in the society. As one of participants mentioned, "It is impossible to access true figures and the numbers of children being abused every day. Many of children have fear of disclosing, often when they unveil such events, they are not believed". Another participant stated, "Some parents do not see the child as a person, they remain busy to fulfill their own needs and desires rather than their children, parenting style stay aggressive and this may include shouting and intimidation". The participants indicated many incidents involved in child abuse in their personal, social, emotional and academic life. Another participant narrated, "We take physical abuse as normal conduct at home and educational institution, for instance hitting, slapping or stirring with an object is not a serious concern. Children are traffic head in to abuse by perpetrators in schools, or religious institutions".

The participants discussed about a range of issues which lead to child abuse. There is not a single factor which results in abuse or neglect of a child; it is usually a combination of various factors. One of the participant highlighted that our culture encouraged harsh physical punishment of children. As he stated, "Roots of child abuse are in our culture and we take child as our property". Mostly physical abuse against child is undertaken with the intent to punish. One of the participants indicated an incident in which a child lost both his arms due to physical abuse by teacher. The parenting style is also very sick. Parents set high expectations from 
their children which are clearly beyond child' s capability however this failure of expectations lead towards frustration which results in child abuse. Moreover it also creates frustration among children. As one of participants highlighted my cousin committed suicide due to not securing high marks in matriculation. The Participants also pointed out that poverty and child abuse was co-related. Unemployment and financial difficulties were linked with growing rates of child abuse. As one participants said, "Family structure and parental employment status matter as well". The child abuse is increasing in our country which decreases their welfare benefit level. One female participant elaborated, "Poverty can increase the likelihood of child abuse, especially when poverty is combined with other risk factors such as depression and social isolation".

After detailed discussion, the participants highlighted specific factors which contributed to child abuse among primary students. The participants generally agreed that overcrowded family or large family size, unintended pregnancies, low level of education of parents are also responsible for child abuse. As a participant mentioned, "There is an increased risk of physical violence during pregnancy, this also results in poorer maternal mental health and lower mother child relationship quality". One of the participants said, "Child in a large family has greater responsibility at early age. When child does not fulfill his responsibility he has to face physical as well as emotional abuse". As another participant added and concluded, "Mostly non-serious students in studies belong to large and poor families".

The participants discussed that there is no proper teacher trainings were conducted to reduce the risk factors lead to child abuse. Special trainings should be conducted in this regard. Ethical and moral trainings should be made part of syllabus. The trainings regarding strong character building should be imparted in school education. The parents should also be trained on how to deal the children. Children should not be neglected at any cost.

\section{Summary of Interviews}

\section{Existing Level of Child Abuse}

The cardinal point of discussion was to know about the perception of participants regarding existing level of child abuse, ill-treatment and neglect at primary schools. The objective of discussion was to look out for the views and observation of parents about the issue of child abuse and child neglect at primary school level. Interviews with parents disclosed several experiences and observation regarding child abuse or child maltreatment. The interview was divided into four sub categories (1) Presence of Physical Abuse (2) Presence of Emotional Abuse (3) Presence of Psychological Abuse (4) Existence of Sexual Abuse

\section{Presence of Physical Abuse}

The participants expressed deep concerns regarding physical abuse in which child was the main victim at school and home as well. They had the opinion, "Children encounter non accidental injury that is the result of hitting, slapping, whipping, 
kicking on anything that is painful for child's body". They reported, "Sometimes parents and teachers expressed their frustration by beating or hitting the children". As a respondent quoted an incident that a child lost his life brutally hitting by his class teacher. The respondents expressed with grief, "Some children exhibited the signs of physical abuse such as bruise marks in form of an object such as stick or hand or burn marks from cigarettes on exposed areas".

\section{Presence of Emotional Abuse}

The respondents were of view that it was the most difficult to identify Emotional Abuse. The respondents pointed out, "Emotional abuse is commonly practiced in every school by every teacher. Mostly slow learner students are always victim of this emotional abuse." The respondents were agreed that slow learner children left the school due to discouraging attitude teachers. As a respondent mentioned, "Parents and teachers do not take child as a complete self, Student's degradation in front of whole class is a common trend in our society". As a participant shared, "Teacher makes a lot of sarcastic comments. It decreases a student's self-esteem and confidence". The ways which are used in emotional abuse are shouting or acting aggressive so students feel humiliated. As a respondent mentioned "Sometimes teacher and parents adopt discriminating behavior with children at classroom and home. They do not treat children according to their needs".

\section{Presence of Psychological Abuse}

The Participants were agreed that children were suffering from anxiety and chronic depression which was the result of psychological abuse. Psychological abuse has more adverse impact as compared to physical abuse. As a participant shared, "Psychological abuse affects inner thought and feeling as well as exerts control over life". As a respondents claimed, "Teachers develop hostile behavior towards children, this creates such feeling among the children as they have no worth and they undermine their selfesteem". The main source of psychological abuse is the rejection of self. Usually parents and teachers do not give much importance to belongingness of their children and students. As a participant shared, "When a child isolates himself from his friends or company he likes, such isolation has devastating effects on child's personality". As another participant mentioned, "Teachers scorn the children, they disgrace, ridicule and humiliate the children". Absence of emotional response is also involved in Psychological base. As a respondent shared, "Teachers show unsympathetic attitude towards the children, ignore emotional needs, avoid visual contact and verbal communication". Sometimes parents convey such remarks unconsciously which can hurt the child severely. For incidence parent says to child, "I wished you were never born and mocking at child by saying you are stupid".

\section{Presence of Sexual Abuse}

The respondents showed great concern regarding sexual abuse of children. The Respondents were agreed, "Use of child for sexual stimulation is highly unethical, 
and child can be victim of sexual abuse at school and home as well". Increasing ratio of children's sexual abuse incidents in society is very alarming. Moreover children are not safe at any place. One of the participants shared an incident hesitantly that a minor school girl of primary level was being victimized by school peon. However such incidents show negligence of class teachers as they do not pay attention to absence of children from classes. Children are also victimized in mosque which is a very shameful and dark aspect of our society. As a respondent shared an incident in which a child was sexually abused by a senior student in Maddrassah. A respondent mentioned, "Ratio of sexual abuse is increasing in society because we do not want to discuss such issues publically". Another participant concluded, "Sexual abuse shows the mental sickness of our society". The participants of the interview were generally agreed that emotional and psychological abuse was also the reason of sexual abuse. When a child feels himself worthless and unwanted, he gets attracted towards any person who gives him undue attention.

\section{Conclusion and Recommendations}

The Participants of the study showed deep concerns about deliberate behavior intended to hurt the child either physically, emotionally or psychologically by parents, teachers, care takers and other adults. The true figures of the victims may be difficult to analyze because the people are hesitant to report such events which go unrecognized and registered. Additionally, parents and teachers make use of violence for upbringing of their child which is highly unethical. An increasing number of children are subjected to such abuse on a regular basis.

The Participants recognized many factors lead to child abuse. They felt disturbing as society encourages violence for the upbringing of children. The violence may lead to visible physical disabilities in children. Moreover, a failure to achieve unrealistically high expectations of teachers and parents by the children is another factor which encourages violence. There are many reported incidents in which the children committed suicide when they were unable to achieve beyond a score set by the teachers and their parents. Another factor includes poverty in association with heightened emotions such as frustration and depression. Children below poverty line are expected to bear abuse. Some other factors are also visible such as families with large members including unplanned pregnancies while uneducated parents are also bound to react harshly to their children. An increasing number of children are subjected to child abuse on a regular basis. Usually teachers may make use of child abuse for maintaining classroom discipline or as a tool for punishment which sometimes may lead to visible physical disabilities in children.

The incidents of humiliation may also be faced at home depending upon extreme behaviors by parents. It was acknowledged that humiliation and lack of self-esteem may lead to emotional and psychological abuse which usually results in anxiety, panic and depression. Finally, the study admitted that children were also victim to sexual abuse at home, schools, Maddrassah and even at the hands of various individuals in the society. It is suggested that; 
1. Child abuse of all type should be prohibited in primary schools; Government should take strict action against persons who involve in child abuse.

2. Punjab Government should pass an act of child protection like KPK Government and implement immediately.

3. There should be training session for awareness of teachers and head teachers to reduce child abuse. 


\section{References}

Ba-Saddik, A. S., \&Hattab, A. S. (2012). Emotional abuse towards children by schoolteachers in Aden Governorate, Yemen: A cross-sectional study. BMC public health, 12(1), 647.Bosede, A. F. (2010). Broken homes and child abuse. Pakistan Journal of Social Sciences, 7(3), 240-243.

Cheah, I. G. S., \&Choo, W. Y. (2016).A review of research on child abuse in Malaysia. Medical journal of Malaysia, 71(1), 87-99.

Dlamini, P. S., Kohi, T. W., Uys, L. R., Phetlhu, R. D., Chirwa, M. L., Naidoo, J. R., ... \&Makoae, L. N. (2007). Verbal and physical abuse and neglect as manifestations of HIV/ AIDS stigma in five African countries. Public Health Nursing, 24(5), 389399.

Durrant, J., \&Ensom, R. (2012). Physical punishment of children: lessons from 20 years of research. CMAJ, 184(12), 1373-1377.

Grant, J., Indermaur, D., Thornton, J., Stevens, G., Chamarette, C., \&Halse, A. (2017).Intrafamilial adolescent sex offenders: psychological profile and treatment.

Meintjes, I., Field, S., Sanders, L., van Heyningen, T., \&Honikman, S. (2010). Improving child outcomes through maternal mental health interventions. Journal of Child and Adolescent Mental Health, 22(2), 73-82.

Pur, H. J., Liman, M. A., \& Ali, D. G. (2016).Students' Perception of Causes and Effect of Teachers' Psychological Abuse in Senior Secondary Schools in Borno State, Nigeria. Journal of Education and Practice, 7(29), 111-119.

Rees, C. A. (2010). Understanding emotional abuse. Archives of disease in childhood, 95(1), 59-67.

Sooryanarayana, R., Choo, W. Y., Hairi, N. N., Chinna, K., Hairi, F., Ali, Z. M., ...\&Mohamad, R. (2017). The prevalence and correlates of elder abuse and neglect in a rural community of Negeri Sembilan state: baseline findings from The Malaysian Elder Mistreatment Project (MAESTRO), a population-based survey. BMJ open, 7(8), e017025.

Tanaka, M., Georgiades, K., Boyle, M. H., \& MacMillan, H. L. (2015). Child maltreatment and educational attainment in young adulthood: Results from the Ontario Child Health Study. Journal of interpersonal violence, 30(2), 195-214 